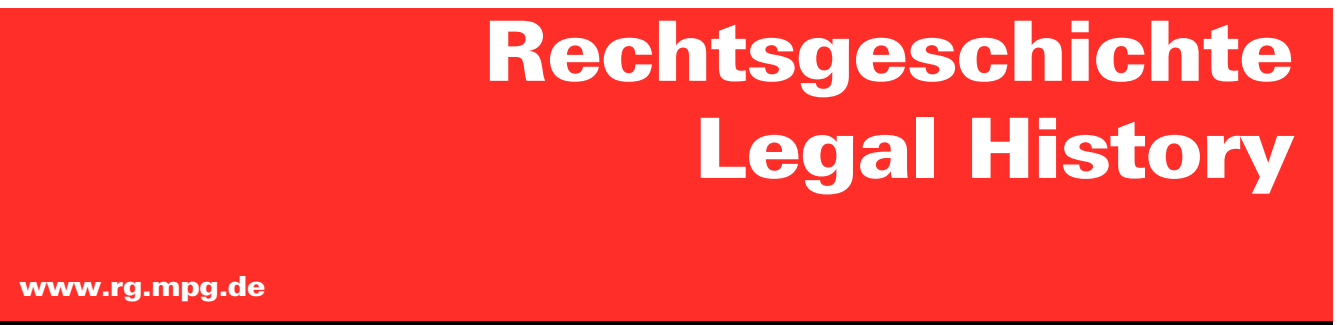

http://www.rg-rechtsgeschichte.de/rg26

$\operatorname{Rg} 26_{2018}$

$447-448$

Zitiervorschlag: Rechtsgeschichte - Legal History Rg 26 (2018)

http://dx.doi.org/10.12946/rg26/447-448

\title{
Antoni Lahondès*
}

\section{Sujets et souverain}

Interdépendances dans l'Empire britannique du XVIII ${ }^{\mathrm{e}}$ siècle

[Subjects and Sovereign. Bonds of Belonging in the $18^{\text {th }}$-century British Empire]

\footnotetext{
* Université de Montréal / Université Paris II Panthéon-Assas, antoni.lahondes@umontreal.ca
}

Dieser Beitrag steht unter einer Creative Commons cc-by-nc-nd 3.0 @creative $(1) \Theta \Theta$ 


\title{
Antoni Lahondès \\ Sujets et souverain*
}

\author{
Interdépendances dans l'Empire britannique du XVIII ${ }^{\mathrm{e}}$ siècle
}

L'ouvrage d'Hannah Weiss Muller explique les liens qui unissent les sujets et leur souverain dans l'Empire britannique du XVIII ${ }^{\mathrm{e}}$ siècle. Le statut de sujet du roi conférait une certaine protection des droits, garantissait des privilèges et pourvoyait une liberté politique souvent enviée, comme le rappelle l'auteure, par des intellectuels européens, notamment français.

Or, ce lien qui unissait chaque Anglais à son souverain, tel qu'il s'est construit depuis le Moyen Âge (en particulier après Conquête normande de 1066) est à l'épreuve des grands changements politiques et démographiques du XVIII ${ }^{\mathrm{e}}$ siècle, autant en métropole que dans ses colonies. L'Acte de l'Union de 1707 forme la Grande-Bretagne à partir de l'Angleterre et de l'Écosse. Dès lors, on parlera de sujets britanniques plutôt qu'anglais. Au cours du XVIII ${ }^{\mathrm{e}}$ siècle, l'Empire colonial britannique s'étend considérablement. Il est question dans cet ouvrage des habitants de Gibraltar et de Minorque (acquises par le Traité d'Utrecht de 1713), du Canada et de Grenade (acquis par le Traité de Paris de 1763), et enfin du Bengale. L'Empire compte alors une population de plus en plus importante et hétérogène, ce qui va mettre à l'épreuve ce statut de sujet. En effet, il ne faut pas entendre seulement »sujet« par »assujetti«, mais plutôt par »citoyen«. Toute personne assujettie (au sens générique du mot) n'est pas nécessairement sujette, ceux qui sont assujettis sans être sujets du roi, sont généralement appelés les »habitants«. Les populations indigènes sont assujetties à l'autorité de leur puissance coloniale, le plus souvent sans être des sujets du roi. Elles sont uniquement abordées sous l'angle de l'attribution éventuelle de ce statut, ou du moins de certaines de ses caractéristiques. Les esclaves sont quant à eux hors du champ de l'étude car il n'était pas question que des droits, et encore moins que le statut de sujet ne leur fussent accordés.
L'extension de ce statut à tous les habitants de l'Empire, ou bien le fait de le réserver aux seuls »vrais Britanniques" est donc à la fois une question de droit privé (statut personnel) et une question structurelle, politique.

Dans les deux premiers chapitres, l'auteure remonte à l'Angleterre médiévale, où ce statut est avant tout synonyme d'allégeance au roi, qui protège en contrepartie ses sujets. Alors que la sujétion est étendue au XVII $^{\mathrm{e}}-\mathrm{XVIII}{ }^{\mathrm{e}}$ aux Écossais et à d'autres peuples des colonies, les lois et la jurisprudence qui régissent ce statut vont s'enrichir. Les éléments déjà présents au Moyen Âge vont alors connaître un renouveau (telle la protection offerte par la Magna Carta, 1215), puis seront renforcés (Déclaration des droits, 1689). Le statut de sujet sera étendu aux Écossais nés après 1603, date de l'Union des Couronnes (Calvin's Case, 1608): puisque le même souverain règne sur l'Écosse et l'Angleterre, les enfants qui naissent dans ces royaumes (droit du sol) deviennent sujets du roi d'Écosse et d'Angleterre (Jacques VI/I). Le statut De Natis Ultra Mare (1351) accordait le statut de sujet aux enfants nés de parents anglais à l'étranger (droit du sang).

Ce »corps de droits" garanti par ces Chartes anglaises octroie droits et privilèges aux sujets de Sa Majesté. La double dimension historique: union entre le sujet et le souverain (allégeance) et les privilèges et libertés des sujets (octroyés et protégés par le roi) est mise en perspective, au XVIII ${ }^{\mathrm{e}}$ siècle, de part et d'autre de l'Empire. Aussi sommes-nous emmenés en "Méditerranée britannique« (troisième chapitre), principalement à Gibraltar et Minorque où apparaît l'opposition entre sujets »réels« et "prétendus«. Les premiers sont les »vrais anglais«, les sujets "prétendus« sont ceux parmi la population autochtone qui aspirent à la protection du roi, alors que ce statut n'est accordé qu'à ceux

\footnotetext{
* Hannah Weiss Muller, Subjects and Sovereign: Bonds of Belonging in the Eighteenth-Century British Empire, Oxford, New York: Oxford University Press 2017, 344 p.,

ISBN 978-0-19-046581-0
} 
qui sont nés après la capture de ces territoires. Dans cette première moitié du XVIII ${ }^{\mathrm{e}}$ siècle, on entrevoit, à partir de cas bien présentés, les défis auxquels serait confrontée une sujétion trop étendue: Londres doit-elle porter secours aux habitants de ses territoires lorsqu'ils sont capturés par des corsaires? S'ils sont sujets, oui, d'autant qu'ils n'hésitent pas, loin de la métropole, à se prévaloir des privilèges que leur confere ce statut. Les autorités britanniques ont alors davantage de responsabilités. En accordant au plus grand nombre ce statut de sujet, la vocation commerciale de ces colonies est dépassée, elles deviennent ainsi des territoires à intégrer politiquement.

Les deux derniers chapitres (4 et 5) portent sur la seconde partie du XVIII ${ }^{\mathrm{e}}$ siècle, durant laquelle l'Empire connut une transformation considérable, avec la conquête puis l'intégration en son sein de populations non-britanniques, non-protestantes, mais chrétiennes, telles que les Français du Canada et de Grenade. Lors de la conquête de ces territoires, les Britanniques s'étaient engagés à ce que les Français qui souhaiteraient y rester deviennent »sujets du roi«, une différenciation apparaît alors entre les »vrais sujets« et »nouveaux sujets« dans ces colonies. Une analyse à la fois juridique et sociologique illustre les rivalités entre ces deux groupes; dans le cadre des lois et de la "constitution" anglaise, se mêlent intérêts privés contradictoires et oppositions ethno-religieuses. Le principal point d'achoppement est la liberté garantie à ces catholiques par le Traité de Paris (1763) de pratiquer leur religion »en tant que le permettent les loix de la Grande-Bretagne«. Cela doit-il leur accorder exactement les mêmes droits que les Britanniques?

Outre les droits »judiciaires" de ces sujets, la question de la représentation politique que le modèle britannique pourvoit est en jeu. Le système colonial laissait jusqu'alors les Britanniques seuls maîtres des assemblées représentatives qu'ils avaient créées outre-mer. Or, cette population chrétienne d'origine française remet en cause ce "monopole«. Une solution en demi-teinte apparait: leur accorder les droits civils, et leur refuser tout ou partie des droits politiques, ce qui crée deux catégories de sujets.

La situation est encore plus complexe dans la grande région du Bengale, où les Britanniques étendent progressivement leur contrôle à partir de Calcutta, car non seulement un droit, mais aussi des institutions anciennes y sont maintenues, sous le patronage de l'empereur moghol, qui est en quelque sorte un co-souverain. De plus, la population de cette région est très diverse: hindous et musulmans côtoient une population européenne bigarrée. Les autorités et les juristes sont alors confrontés aux défis du pluralisme juridique (autant en droit privé qu'en droit public). Ici, le modèle qui a été étendu outre mesure de l'Écosse au Québec montre ses vraies limites, il ne sera pas extensible à l'infini, et il faut inventer de nouveaux modèles intermédiaires, en fonction du contexte local. Pendant ce temps, l'allégeance des »vrais sujets« se dérobe dans les treize colonies.

Le statut de sujet est souvent représenté sous son meilleur jour. Il pourrait être mis en perspective avec des exemples moins favorables, le peuple acadien a ainsi surtout souffert de son assujettissement. L'ouvrage aurait alors emprunté une direction plus critique. Le style littéraire de cet ouvrage rend sa lecture fluide et agréable, y compris pour des lecteurs dont l'anglais n'est pas la langue première. C'est un voyage dans le temps et dans l'espace, un récit vivant, des airs de Tour du Monde en 80 Jours chez les sujets du XVIII ${ }^{\mathrm{e}}$ siècle. Hannah Weiss Muller a écrit plusieurs articles ainsi que sa thèse de doctorat sur des thèmes voisins. Cette connaissance approfondie du sujet, la »mobilisation« d'un grand nombre de sources primaires, ainsi qu'une belle plume sont les clés de cet alliage réussi qui concilie plaisir de la lecture et apport scientifique. 